Uniciencia. Vol. 29, No. 2, pp. 84-106. Julio-Diciembre, 2015.

\title{
Importación de plaguicidas y peligros en salud en América Central durante el periodo 2005 - 2009
}

Pesticides import and health hazards. Central America, 2005 - 2009

Virya Bravo-Durán

virya.bravo.duran@una.cr

Instituto Regional de Estudios en

Sustancias Tóxicas.

Universidad Nacional.

Costa Rica.

Silvia-Elena Berrocal-Montero

silvia.berrocal.montero@una.cr

Instituto Regional de Estudios en

Sustancias Tóxicas.

Universidad Nacional.

Costa Rica.

Fernando Ramírez-Muñoz

fernando.ramirez.munoz@una.cr

Instituto Regional de Estudios en

Sustancias Tóxicas.

Universidad Nacional.

Costa Rica.

Elba de-la-Cruz-Malavassi

elba.delacruz.malavassi@una.cr

Instituto Regional de Estudios en

Sustancias Tóxicas.

Universidad Nacional.

Costa Rica.
Nonato Canto-Mai

pcbinfo@btl.net

Pesticides Control Board

Cayo District

Belice.

Anabel Tatis-Ramírez

anabeltatis12@yahoo.com

Centro de Investigación e Información de

Medicamentos y Tóxicos.

Universidad de Panamá.

Panamá.

Winston Mejía-Merino

wrmejia@yahoo.com

Departamento de Fisiología.

Universidad

Nacional Autónoma de Honduras.

Honduras.

Teresa Rodríguez-Altamirano

teresar66@gmail.com

Centro de Investigación en Salud, Trabajo

y Ambiente

Universidad Nacional Autónoma de

Nicaragua.

Nicaragua.

Recibido-Received: 19/ago/2014 / Aceptado-Accepted: 10/ene/2014 / Publicado-Published: 31/jul/2015.

Virya Bravo-Durán y otros.

Artículo protegido por licencia Creative Commons: BY-NC-ND / Protected by Creative Commons: BY-NC-ND

Revista de acceso y publicación gratuita/ Access and publication in Uniciencia is totally no fee. 
Uniciencia. Vol. 29, No. 2, pp. 84-106. Julio-Diciembre, 2015. URL: www.revistas.una.ac.cr/uniciencia

Email: revistauniciencia@una.cr
ISSN Electrónico: 2215-3470

DOI: http://dx.doi.org/10.15359/ru.29-2.6

\title{
Resumen
}

Se analizaron datos de importación de plaguicidas agrícolas en América Central, para el quinquenio 2005-2009 para el monitoreo de peligros en salud. La metodología usada ya fue publicada para el análisis del quinquenio 2000-2004 (Bravo et al., 2011). Durante este segundo quinquenio, se importaron 353 ingredientes activos (ia), en una cantidad promedio anual de 39000 ton ia. Catorce ia se importaron en cantidades $\geq 2000$ ton ia y representaron el $77 \%$ de la importación. Las acciones biocidas más usadas fueron los fungicidas y los herbicidas. En estas acciones, los grupos químicos más importados fueron los ditiocarbamatos y los fenoxiácidos, las fosfonoglicinas y los bipiridilos, respectivamente. La cantidad importada de plaguicidas peligrosos correspondió en un $27 \%$ a ia con toxicidad aguda alta a extrema, $35 \%$ con 2 o más efectos tópicos de moderados a severos y $47 \%$ con 4 o más efectos crónicos. Los plaguicidas regulados internacionalmente corresponden al $19 \%$ del total importado. Guatemala fue el país que más plaguicidas importó y Costa Rica continuó liderando indicadores como: $\mathrm{kg}$ i.a./habitante, $\mathrm{kg}$ i.a./habitante rural, $\mathrm{kg}$ ia/trabajador agrícola, $\mathrm{kg}$ ia/ha agrícola. Los datos indicaron que las poblaciones en América Central continúan expuestas a peligros de salud por los plaguicidas importados.

Palabras claves: Importación; plaguicidas; indicadores; peligros; salud.

\begin{abstract}
Agricultural pesticides imported in Central America were analyzed, for period the 2005-2009 in order to monitor health hazards. The methodology used has already been published for the analysis of the period 2000-2004 (Bravo et al., 2011). During 2005-2009, 353 active ingredients (ai) were imported in an average annual amount of 39000 ton ai. Fourteen ai imported in quantities $\geq$ ton ai 2000 accounted for $77 \%$ of imports. The biocidal actions most used were fungicides and herbicides. In these actions, the chemical groups most imported were dithiocarbamates and phenoxyacid the fosfonoglicinas and bipyridyls respectively. The imported quantity of hazardous pesticides corresponded to $27 \%$ ai with extremely high acute toxicity, $35 \%$ with 2 or more topical effects of moderate to severe and $47 \%$ with 4 or more chronic effects. Internationally regulated pesticides amounted to $19 \%$ of total imports. Guatemala was the country with highest amount of imported pesticides and Costa Rica continued leading indicators such as $\mathrm{kg}$ ai / capita $\mathrm{kg}$ ai / rural inhabitant $\mathrm{kg}$ ai / agricultural worker $\mathrm{kg}$ ai / ha farm. Data indicate that populations in Central America continue to be exposed to health dangers of imported pesticides.
\end{abstract}

Keywords: import; pesticides; indicators; hazards; health.

Virya Bravo-Durán y otros.

Artículo protegido por licencia Creative Commons: BY-NC-ND / Protected by Creative Commons: BY-NC-ND

Revista de acceso y publicación gratuita/ Access and publication in Uniciencia is totally no fee. 
Datos confiables sobre cantidades de plaguicidas producidos y usados en el mundo son difíciles de obtener, debido al costo de recopilarlos, sistematizarlos y divulgarlos, así como a los conflictos de intereses que estos productos involucran.

A pesar de ello, algunos autores aportan en sus escritos aproximaciones a estos valores, que sirven como referencia para abordar los problemas que existen en torno a los plaguicidas. García (1998), para la década de los noventa, se refirió a una producción mundial de más de 3000 millones de $\mathrm{kg}$ de plaguicidas por año, facturados en USD \$ 21000 millones y mencionó que, según FAO, un 19\% de la producción (572 millones de kg por año) se utilizaba en países en desarrollo.

El proyecto Aspectos Ocupacionales y Ambientales de la Exposición a Plaguicidas en el Istmo Centroamericano (PLAGSALUD) estimó la producción mundial de plaguicidas, para finales del siglo XX, en 2800 millones de $\mathrm{kg}$ anuales; estos, distribuidos en 900 ingredientes activos (ia) y comercializados en más de 50000 formulaciones, con un valor de USD \$ 40000 millones (PLAGSALUD, 2002). Por su parte, la Agencia de Protección Ambiental de los Estados Unidos (EPA) estimó la producción mundial de plaguicidas en 2364 millones de kg durante el 2007 (Grube et al., 2011).

Mientras que Chapagain-K (2011) indicó una producción mundial de 2700 millones de kg por año en el 2011. De esta producción, en América Central se importaron 34 millones de $\mathrm{kg}$ de plaguicidas en 1994, 45 millones de $\mathrm{kg}$ a finales de la década de los noventa (PLAGSALUD, 2002) y casi 33 millones de $\mathrm{kg}$ ia por año, en el periodo 20002004 (Bravo et al., 2011).

Según datos de la Organización Mundial de la Salud (OMS), dos millones de personas al año se intoxican en el mundo por exposición a plaguicidas, tres cuartas partes pertenecen a los países en desarrollo, donde se utiliza el $25 \%$ de la producción mundial de plaguicidas (Olivera y Rodríguez, 1999).

El Banco Mundial indica que, de acuerdo con la OMS, 355000 personas mueren por año a nivel mundial, de forma no intencional, por exposición a plaguicidas. Dos terceras partes de estas intoxicaciones corresponden a habitantes de países en desarrollo, que no cuentan con buenos sistemas para la regulación de plaguicidas peligrosos (WB, 2008). Weinberg (2009) hace referencia a Watts, quien afirma que la exposición a estos plaguicidas es un problema de salud particularmente grave en gran parte del mundo en desarrollo.

De acuerdo con Wesseling y otros autores, los plaguicidas representan uno de los problemas de salud ocupacional y ambiental más importantes en América Central (Wesseling et al., 2001). Datos de PLAGSALUD para América Central, en la década de los noventa, indican que en esta región anualmente se intoxican alrededor de 7000 personas por plaguicidas en forma aguda, sin contar que por cada caso registrado no se anotan entre 80 a 99; esta entidad también presenta datos de mortalidad para la región que fluctúan entre 867 y 748 fallecidos por año (PLAGSALUD, 2002).

Virya Bravo-Durán y otros.

Artículo protegido por licencia Creative Commons: BY-NC-ND / Protected by Creative Commons: BY-NC-ND

Revista de acceso y publicación gratuita/ Access and publication in Uniciencia is totally no fee. 
En cuanto a los costos de atención médica, García (1998) cita valores máximos de aproximadamente USD \$100 per cápita para la atención y el tratamiento de las intoxicaciones agudas por plaguicidas en América Central, para la misma década e indica que estos costos dependen de la gravedad de la intoxicación, el tipo de atención y la estancia hospitalaria.

Otros autores indican que los responsables políticos pueden reducir la accesibilidad a los agroquímicos más peligrosos y que esto reduciría los costos en salud causados por las intoxicaciones con plaguicidas. Opinan que esto se puede hacer a través de campañas de información y de la regulación del uso o prohibición de estos (WB, 2008).

En el Instituto Regional de Estudios en Sustancias Tóxicas (IRET) se considera que los datos de cantidades importadas de plaguicidas son básicos para determinar su carga ambiental e identificar los peligros que ellos representan para la salud y el ambiente en poblaciones específicas. De esta forma se pueden tomar decisiones que ayuden en la vigilancia epidemiológica y en la regulación del uso de plaguicidas peligrosos.

Países desarrollados como Suecia, a través de la Agencia de Productos Químicos (KemI), y los Estados Unidos, a través de la EPA y del Servicio Nacional de Estadísticas Agrícolas (NASS), han implementado sistemas informáticos que integran datos de cantidades de plaguicidas y montos de su comercialización por año, para ser utilizados en en el desarrollo de indicadores y la vigilancia de las tendencias. En algunos casos estos sistemas también incluyen datos de uso de plaguicidas por cultivo y área tratada (Bravo et al., 2011).

En países en desarrollo como los nuestros, también existen iniciativas de sistematización de datos de plaguicidas. Un ejemplo lo constituye la Comisión Económica de las Naciones Unidas para América Latina y el Caribe (CEPAL), que recoge datos de plaguicidas de cuatro acciones biocidas (herbicidas, fungicidas, insecticidas y bactericidas) desde 1990 y los publica en Anuarios Estadísticos accesibles por internet (ECLA, 2012). Una limitante de la publicación es la omisión ocasional de datos para ciertos años y países.

El IRET sistematiza datos de importación de plaguicidas en Costa Rica desde 1977 y de uso desde 1985. Este mismo Instituto recogió y sistematizó datos de América Central a finales de la década de los ochenta y retomó esta labor a partir del 2000; primero, dentro del contexto del Programa de Investigación en Salud y Ambiente para América Central (SAREC) y luego, en el 2003, a través del proyecto "Vigilancia de importación y uso de plaguicidas", en el componente "Bases de datos y monitoreo de exposición y efectos" del Programa Salud y Trabajo en América Central (SALTRA).

Información obtenida por este proyecto, para el periodo 2000-2004, indica que Belice, Guatemala, Honduras, El Salvador, Nicaragua, Costa Rica y Panamá importaron casi 33 millones de $\mathrm{kg}$ de plaguicidas por año, de 403 ingredientes activos. Trece ia representaron un $77 \%$ de la cantidad total importada. El 22\% de esta cantidad correspondió a plaguicidas clasificados como de alta a extremadamente peligrosos según su toxicidad aguda, el $33 \%$ fueron plaguicidas con dos o más efectos tópicos de moderados o severos y el 30\% tenían cuatro o más efectos por toxicidad crónica (Bravo et al., 2011).

Virya Bravo-Durán y otros.

Artículo protegido por licencia Creative Commons: BY-NC-ND / Protected by Creative Commons: BY-NC-ND

Revista de acceso y publicación gratuita/ Access and publication in Uniciencia is totally no fee. 
En seguimiento de esta línea base, al terminar la fase I de SALTRA, se gestó en el IRET otro proyecto de investigación denominado "Vigilancia del uso de plaguicidas como indicador de peligros para la salud". Este se adscribió al Programa de Actividades Permanentes del IRET (PAP fase II) y posteriormente fue incluido en SALTRA fase II.

Este proyecto buscó mejorar los análisis cuantitativos para que los tomadores de decisiones y el público en general tuvieran acceso no solo a nuevos, sino a mejores datos. Este artículo es uno de los productos de divulgación del proyecto mencionado, en él se aportan datos de las cantidades importadas de plaguicidas en América Central para el periodo 2005-2009 y se actualizan los indicadores de peligro para la salud humana.

\section{Metodología}

Se solicitaron las bases de datos de importación de plaguicidas, para el quinquenio comprendido entre 2005 y 2009, a las instituciones rectoras del sector agropecuario de cada país en América Central. Belice, Guatemala, Honduras, El Salvador, Costa Rica y Panamá enviaron todas las bases solicitadas para su depuración y análisis en IRET.

Respecto a Guatemala no se contó con la información correspondiente al segundo semestre del 2009 y de Nicaragua con la correspondiente a los años 2008 y 2009. Sin embargo, con la información obtenida de estos países para años anteriores, se realizaron aproximaciones de las cantidades importadas en ton ia/año. En total se analizaron 33 bases de datos de cantidades importadas de plaguicidas organizadas por año y país.

La metodología utilizada para la depuración de las bases de datos, el cálculo de la cantidad importada de plaguicidas y el desarrollo de los indicadores de peligro para la salud es la usada para los análisis del periodo 2000-2004, la cual ya fue publicada ( Bravo et al., 2011). En síntesis los procedimientos metodológicos fueron:

1. Unificación de los datos por año y país.

2. Identificación de errores de caracterización de la importación, nomenclatura de productos comerciales o ingredientes activos, clasificación por acción biocida, composición de productos comerciales, reporte de cantidades importadas, unidades de medida, ETC.

3. Depuración de errores a través del uso de los registros de plaguicidas de cada país, las páginas web de las casas comerciales de plaguicidas, bases de plaguicidas (http://www.plaguicidasdecentroamerica.una.ac.cr/; http://www.eu-footprint.org/ppdb.html) y el contacto con funcionarios de las instituciones rectoras de la importación de plaguicidas de los siete países, que evacuaron dudas y suministraron la información faltante.

4. Cálculo de cantidades de plaguicidas importadas (ton ia total/país/año y ton ia promedio/país/quinquenio), número de ingredientes activos y cantidad importada por categoría de importación (ton ia total/región/quinquenio) y cantidad de plaguicidas importada por acción biocida y grupo químico (ton ia total/región/año y quinquenio). 
Uniciencia. Vol. 29, No. 2, pp. 84-106. Julio-Diciembre, 2015. URL: www.revistas.una.ac.cr/uniciencia

5. Caracterización de ingredientes activos por toxicidad aguda (EPA y OMS), tópica (irritación dérmica y ocular y potencial alergénico) y crónica (carcinogenicidad según la Agencia Internacional de investigaciones sobre el cáncer (IARC) y EPA, neurotoxicidad, mutagenicidad, teratogenicidad, genotoxicidad y disrupción endocrina de acuerdo con la clasificación de la Unión Europea) (Bravo et al., 2011; de la Cruz, Bravo y Ramírez., 2013; University of Hertfordshire, 2012).

6. Desarrollo de indicadores generales por habitante, habitante rural, trabajador agrícola y superficie agrícola (arables + permanentes) ( $\mathrm{kg}$ ia promedio/año/país) (Bravo et al., 2011; Partanen y Aragón, 2009; ECLA, 2012; BM, 2013). En este artículo se agregó un nuevo indicador para la superficie pecuaria, puesto que en la cobertura de pastos también se usan plaguicidas, principalmente herbicidas (Bravo et al., 2013).

El indicador por trabajador agrícola para Guatemala y Costa Rica se ajustó restando de la cantidad de plaguicidas importada un $35 \%$ y un $25 \%$ respectivamente; esto para compensar la cantidad exportada por la industria formuladora y envasadora de estos países, a la cual ya no estarán expuestos sus trabajadores agrícolas (Larios, 2011; Ramírez, Chaverri, de la Cruz, Wesseling, Castillo y Bravo, 2009).

El indicador por habitante rural, no se ajustó con la exportación, debido a que algunas instalaciones de formuladoras y envasadoras en estos países se ubican en áreas rurales, lo que trae consigo la posibilidad de exponer a la población rural con las emisiones de sus procesos productivos y el transporte de las materias primas o productos.

7. Desarrollo de indicadores de salud por toxicidad con mayor peligrosidad, como la aguda de alta a extrema, tópica con $\geq 2$ efectos de moderados a severos y crónica con $\geq 4$ efectos (ton ia total y promedio/región/año y quinquenio) (Bravo et al., 2011; de la Cruz et al., 2013; University of Hertfordshire, 2012).

8. Desarrollo de indicadores de cumplimiento de normas internacionales (ton ia total/región/año y quinquenio) como las que incluyen la "Docena Sucia" de la Red de Acción en Plaguicidas (PAN) (PAN, 2009), los "Doce a prohibir o restringir" según el Acuerdo No 9 de la XVI Reunión de Ministros del Sector Salud de Centroamérica y República Dominicana (RESSCAD) (Nieto, 2001), los PIC o plaguicidas y productos químicos peligrosos (Secretaría del Convenio de Rotterdam, 2004), los COPs o contaminantes orgánicos persistentes (Secretaría del Convenio de Estocolmo, 2009) y las sustancias que agotan la capa de ozono (Secretaría del Ozono, 1997).

Adicionalmente, en este estudio se definió un grupo de plaguicidas peligrosos, constituido por los ingredientes activos de las clases de toxicidad con mayor peligrosidad importados en cantidades > 1000 ton ia/región/quinquenio. 
Uniciencia. Vol. 29, No. 2, pp. 84-106. Julio-Diciembre, 2015. URL: www.revistas.una.ac.cr/uniciencia

Email: revistauniciencia@una.cr
ISSN Electrónico: 2215-3470

DOI: http://dx.doi.org/10.15359/ru.29-2.6

\section{Resultados}

Durante el periodo 2005-2009 en América Central se importaron en total 353 ingredientes activos, equivalentes a 183047 ton (tabla 1). Este valor fue subestimado por los datos faltantes de Guatemala y Nicaragua, pero de ser ajustado con aproximaciones a estos datos, el valor podría llegar a 195047 ton ia/quinquenio/región.

Del total de los ingredientes activos importados en la región, los siguientes catorce se importaron en cantidades $\geq 2000$ ton ia/quinquenio: mancozeb (36 779 ton ia), 2,4-D (24 917 ton ia), glifosato (22 561 ton ia), paraquat (17 800 ia), bromuro de metilo 492 ton ia), clorotalonil (5 565 ton ia), atrazina (4 745 ton ia), metam sodio (3 947 ton ia), diuron (3 820 ton ia), tridemorf (3 386 ton ia), ametrina (2 828 ton ia), 1,3-D (2 686 ton ia), terbufos (2 540 ton ia) y propineb (2 283 ton ia).

Estos representaron aproximadamente el $77 \%$ de la importación total de plaguicidas, el restante $23 \%$ correspondió a 339 ingredientes activos importados en cantidades < 2000 ton ia/quinquenio (tabla 1).

Tabla 1

Número y cantidad de plaguicidas importados en América Central por categoría de importación, entre 2005 y 2009

\begin{tabular}{cccc} 
Clases de importación & Ingredientes activos & \multicolumn{2}{c}{ Cantidad importada } \\
ton ia & ia & 140348 & 76,7 \\
$\geq 2000$ & 14 & 19196 & 10,5 \\
$\geq 1000 \mathrm{a}<2000$ & 13 & 7425 & 4,1 \\
$\geq 500 \mathrm{a}<1000$ & 11 & 12145 & 6,6 \\
$\geq 100 \mathrm{a}<500$ & 47 & 3915 & 2,1 \\
$\geq 1 \mathrm{a}<100$ & 176 & 18 & 0,01 \\
$<1$ & 92 & $\mathbf{1 8 3 0 4 7}$ & $\mathbf{1 0 0 , 0}$ \\
Total & $\mathbf{3 5 3}$ & &
\end{tabular}

Fuente: Datos propios de la investigación.

Entre 2005 y 2009, Honduras (3 069 - 4564 ton ia/año), Costa Rica (11 496 - 12 291 ton ia/año) y Belice (408 - 514 ton ia/año) presentaron incrementos en la cantidad total de plaguicidas importada; mientras que Panamá (3 157 - 2433 ton ia/año) y El Salvador (1 737 - 1286 ton ia/año) la redujeron. De 2005 a 2008 Guatemala mostró un incremento (13 051 - 13955 ton ia/año) y Nicaragua de 2005 a 2007 una disminución (3 687 - 3233 ton ia/año) (figura 1).

Virya Bravo-Durán y otros.

Artículo protegido por licencia Creative Commons: BY-NC-ND / Protected by Creative Commons: BY-NC-ND

Revista de acceso y publicación gratuita/ Access and publication in Uniciencia is totally no fee. 
Uniciencia. Vol. 29, No. 2, pp. 84-106. Julio-Diciembre, 2015. URL: www.revistas.una.ac.cr/uniciencia

Email: revistauniciencia@una.cr
ISSN Electrónico: 2215-3470

DOI: http://dx.doi.org/10.15359/ru.29-2.6

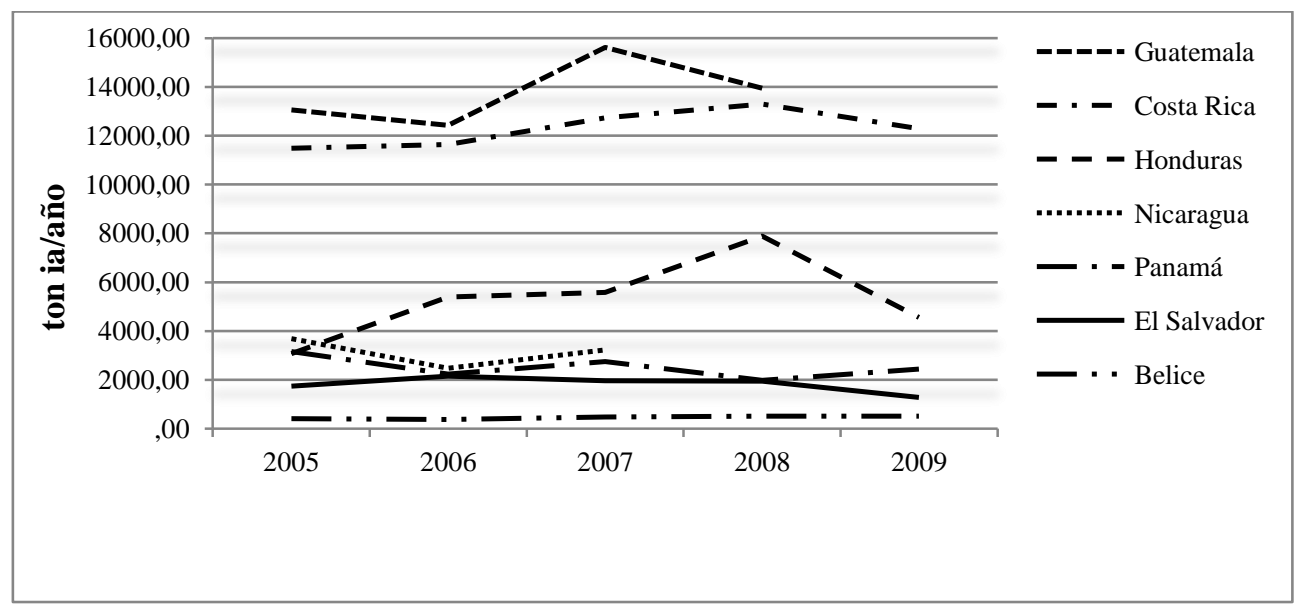

Figura 1.

Cantidad de plaguicidas importada en América Central, entre 2005 y 2009.

Fuente: Datos propios de la investigación.

Comparando los promedios anuales de las cantidades de plaguicidas importadas en cada uno de los países en la región centroamericana durante los dos quinquenios estudiados, se encontró que todos los países con excepción de Honduras mostraron incrementos en sus importaciones; las cuales fueron mayores en Guatemala y Costa Rica, países que, además, alternaron la primera y segunda posición de un quinquenio al otro. En Honduras, Nicaragua, Panamá, El Salvador y Belice se observó una tendencia a mantener sus lugares (figura 2). El incremento del promedio anual de las cantidades de plaguicidas importadas por Nicaragua, a pesar de corresponder a un periodo de solo tres años, también fue alto con respecto al valor del quinquenio anterior 2000-2004 (Bravo et al., 2011). En general, se calculó el promedio anual de la cantidad de plaguicidas importada en América Central de 2005 a 2009 en 37000 ton ia/año, excluyendo los datos faltantes de Guatemala (6 meses) y Nicaragua (2 años).

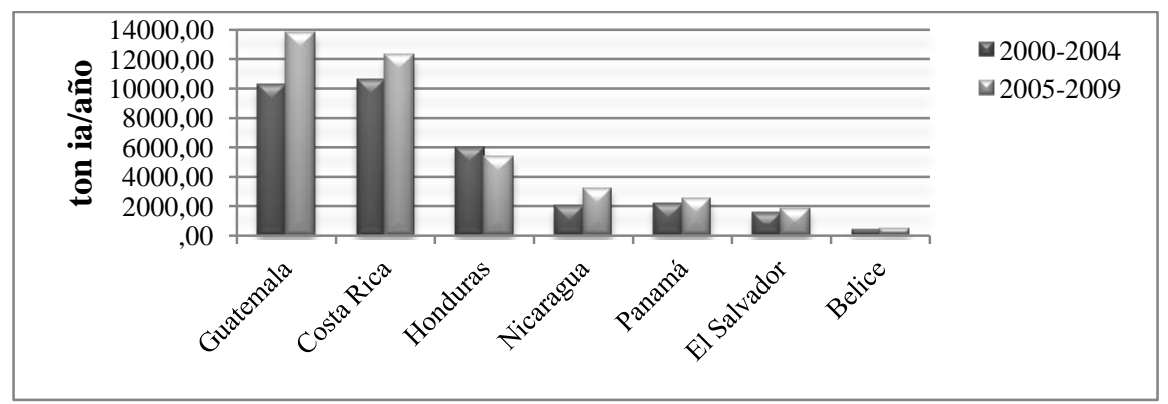

Figura 2.

Cantidad promedio anual de plaguicidas importada en América Central, durante dos quinquenios. Datos propios de la investigación.

Fuente: Datos propios de la investigación.

Virya Bravo-Durán y otros.

Artículo protegido por licencia Creative Commons: BY-NC-ND / Protected by Creative Commons: BY-NC-ND

Revista de acceso y publicación gratuita/ Access and publication in Uniciencia is totally no fee. 
Uniciencia. Vol. 29, No. 2, pp. 84-106. Julio-Diciembre, 2015. URL: www.revistas.una.ac.cr/uniciencia

Email: revistauniciencia@una.cr
ISSN Electrónico: 2215-3470

DOI: http://dx.doi.org/10.15359/ru.29-2.6

En total, las cantidades de plaguicidas importadas fueron más altas para los herbicidas y los fungicidas que para otras acciones biocidas (tabla 2), puesto que de 2005 a 2009 se importaron en América Central 86315 ton ia de herbicidas (47\%), 59656 ton ia de fungicidas (33\%), 14483 ton ia de fumigantes (8\%), 12562 ton ia de insecticidas (7\%) y 8 317 ton ia de nematicidas $(5 \%)$.

Las importaciones de otras acciones biocidas correspondieron a 1713 ton ia (1\%). Los ingredientes activos más importados por acción biocida fueron: 2,4-D (herbicida), mancozeb (fungicida), bromuro de metilo (fumigante), metamidofos (insecticida) y terbufos (nematicida).

Tabla 2

Cantidad de plaguicidas importada en América Central por acción biocida, entre 2005 y 2009

\begin{tabular}{|c|c|c|c|c|c|c|c|}
\hline \multirow{2}{*}{$\begin{array}{l}\text { Acción } \\
\text { biocida }\end{array}$} & \multicolumn{6}{|c|}{ Cantidad importada (ton ia) } & \multirow{2}{*}{$\begin{array}{l}\text { Plaguicidas más } \\
\text { importados }\end{array}$} \\
\hline & 2005 & 2006 & 2007 & 2008 & 2009 & Total & \\
\hline Herbicidas & 16847 & 16920 & 21422 & 18805 & 12320 & 86315 & $\begin{array}{l}\text { 2,4-D, glifosato y } \\
\text { paraquat }\end{array}$ \\
\hline Fungicidas & 11496 & 11842 & 13069 & 12770 & 10479 & 59656 & $\begin{array}{l}\text { mancozeb, clorotalonil y } \\
\text { tridemorf }\end{array}$ \\
\hline Fumigantes & 3231 & 3483 & 2894 & 3207 & 1668 & 14483 & $\begin{array}{l}\text { bromuro de metilo, } \\
\text { metam sodio y } \\
\text { dicloropropeno }\end{array}$ \\
\hline Insecticidas & 3189 & 2208 & 2697 & 2614 & 1855 & 12562 & $\begin{array}{l}\text { metamidofos, diazinon y } \\
\text { clorpirifos }\end{array}$ \\
\hline Nematicidas & 1603 & 1831 & 1910 & 1746 & 1227 & 8317 & $\begin{array}{l}\text { terbufos, etoprofos y } \\
\text { oxamil }\end{array}$ \\
\hline Bactericidas & 158 & 345 & 224 & 281 & 152 & 1159 & ácido crómico \\
\hline Otros & 82 & 90 & 131 & 149 & 102 & 554 & etefon \\
\hline Total & 36606 & 36719 & 42347 & 39572 & 27803 & 183047 & \\
\hline
\end{tabular}

Fuente: Datos propios de la investigación.

Los grupos químicos que lideraron la importación de plaguicidas de 2005-2009 fueron los ditiocarbamatos (22\%), los fenoxiacéticos (14\%), las fosfonoglicinas (13\%), los bipiridilos (10\%), los organofosforados $(8 \%)$, las triazinas $(5 \%)$, los alifáticos bromados (4\%) y los benzonitrilos (3\%), que juntos representan un $78 \%$ del total importado.

Los ingredientes activos más importados por grupo químico fueron: mancozeb, 2,4$\mathrm{D}$, glifosato, paraquat, terbufos, atrazina, bromuro de metilo y clorotalonil respectivamente (tabla 3).

Virya Bravo-Durán y otros.

Artículo protegido por licencia Creative Commons: BY-NC-ND / Protected by Creative Commons: BY-NC-ND

Revista de acceso y publicación gratuita/ Access and publication in Uniciencia is totally no fee. 
Uniciencia. Vol. 29, No. 2, pp. 84-106. Julio-Diciembre, 2015. URL: www.revistas.una.ac.cr/uniciencia

Email: revistauniciencia@una.cr
ISSN Electrónico: 2215-3470

DOI: http://dx.doi.org/10.15359/ru.29-2.6

Tabla 3

Cantidad de plaguicidas importada en América Central por grupo químico, entre 2005 y 2009

\begin{tabular}{|c|c|c|c|c|c|c|c|}
\hline \multirow{2}{*}{ Grupo químico } & \multicolumn{6}{|c|}{ Cantidad importada (ton ia) } & \multirow{2}{*}{$\begin{array}{l}\text { Plaguicidas más } \\
\text { importados }\end{array}$} \\
\hline & 2005 & 2006 & 2007 & 2008 & 2009 & Total & \\
\hline Ditiocarbamatos & 6824 & 7566 & 8672 & 8778 & 7546 & 39385 & mancozeb \\
\hline Fenoxiacéticos & 6257 & 5783 & 5797 & 4154 & 3024 & 25015 & $2,4-\mathrm{D}$ \\
\hline Fosfonoglicinas & 3955 & 4042 & 5062 & 6550 & 3405 & 23014 & glifosato \\
\hline Bipiridilos & 2664 & 3063 & 5718 & 3547 & 2867 & 17860 & paraquat \\
\hline Organofosforados & 3704 & 2876 & 3441 & 2941 & 2021 & 14983 & $\begin{array}{l}\text { terbufos, } \\
\text { etoprofos y } \\
\text { metamidofos }\end{array}$ \\
\hline Triazinas & 2114 & 2106 & 2179 & 2134 & 1411 & 9944 & $\begin{array}{l}\text { atrazina, ametrina } \\
\text { y terbutrina }\end{array}$ \\
\hline $\begin{array}{l}\text { Alifáticos } \\
\text { bromados }\end{array}$ & 1745 & 1556 & 1405 & 1071 & 715 & 6492 & bromuro de metilo \\
\hline Benzonitrilos & 999 & 1048 & 1445 & 1267 & 834 & 5594 & clorotalonil \\
\hline Inorgánicos & 1095 & 1280 & 1043 & 1153 & 644 & 5216 & azufre \\
\hline Tiocarbamatos & 896 & 984 & 570 & 1181 & 335 & 3966 & metam sodio \\
\hline Úreas & 576 & 790 & 1052 & 1056 & 398 & 3872 & diuron \\
\hline Morfolina & 830 & 974 & 776 & 606 & 609 & 3795 & tridemorf \\
\hline Carbamatos & 503 & 733 & 710 & 885 & 811 & 3641 & $\begin{array}{l}\text { oxamil, carbaril y } \\
\text { carbofuran }\end{array}$ \\
\hline Alifáticos clorados & 358 & 628 & 609 & 646 & 444 & 2686 & dicloropropeno \\
\hline Organoclorados & 516 & 588 & 526 & 609 & 196 & 2435 & $\begin{array}{l}\text { endosulfan y } \\
\text { cloropicrina }\end{array}$ \\
\hline Dinitroanilidas & 487 & 293 & 526 & 369 & 290 & 1965 & pendimetalina \\
\hline Benzimidazoles & 704 & 311 & 352 & 288 & 219 & 1874 & carbendazina \\
\hline $\begin{array}{l}\text { Conazoles y } \\
\text { triazoles }\end{array}$ & 301 & 298 & 323 & 308 & 274 & 1504 & tebuconazol \\
\hline Piretroides & 413 & 182 & 242 & 177 & 137 & 1151 & cipermetrina \\
\hline Anilidas & 167 & 153 & 182 & 183 & 162 & 848 & $\begin{array}{l}\text { propanil y } \\
\text { metalaxil }\end{array}$ \\
\hline Orgánicos & 125 & 149 & 199 & 66 & 107 & 647 & MSMA \\
\hline Neonicotinoides & 50 & 60 & 70 & 117 & 127 & 425 & imidacloprid \\
\hline Sulfonilúreas & 37 & 40 & 75 & 51 & 53 & 257 & metsulfuron \\
\hline Otros & 1284 & 1215 & 1371 & 1434 & 1173 & 6478 & $\begin{array}{l}\text { picloram y } \\
\text { acetocloro }\end{array}$ \\
\hline Total & 36606 & 36719 & 42347 & 39572 & 27803 & 183047 & \\
\hline
\end{tabular}

Fuente: Datos propios de la investigación.

Virya Bravo-Durán y otros.

Artículo protegido por licencia Creative Commons: BY-NC-ND / Protected by Creative Commons: BY-NC-ND

Revista de acceso y publicación gratuita/ Access and publication in Uniciencia is totally no fee. 
Uniciencia. Vol. 29, No. 2, pp. 84-106. Julio-Diciembre, 2015. URL: www.revistas.una.ac.cr/uniciencia

Email: revistauniciencia@una.cr
ISSN Electrónico: 2215-3470

DOI: http://dx.doi.org/10.15359/ru.29-2.6

La cantidad promedio anual de plaguicidas importada por Guatemala y Costa Rica fue superior a la importada por los otros países ( $>12$ millones de $\mathrm{kg}$ ia), mientras que la cantidad importada por Belice fue la menor ( $<0,45$ millones de $\mathrm{kg}$ ia) (tabla 4). Al comparar los indicadores generales ( $\mathrm{kg}$ ia/habitante/año; $\mathrm{kg}$ ia/habitante rural/año; $\mathrm{kg}$ ia/trabajador agrícola/año; kg ia/ha agrícola/año; $\mathrm{kg}$ ia/ha pecuaria/año) de cada país con los obtenidos para la región, se observó que Costa Rica encabezó la lista, puesto que este país tuvo una importación de plaguicidas 3 veces mayor por habitante, 4 veces mayor por habitante rural y por trabajador agrícola, 6 veces mayor por hectárea agrícola y 3 veces mayor por hectárea pecuaria.

Belice, a pesar de ser el país que menos plaguicidas importó, ocupó el segundo lugar de la región con una importación de plaguicidas 2 veces mayor por habitante, 3 veces mayor por trabajador agrícola, 3 veces mayor por hectárea pecuaria.

Guatemala se ubicó en una tercera posición con importaciones de plaguicidas 2 veces mayor por hectárea pecuaria. Mientras que Panamá con un indicador general de importación anual por trabajador agrícola alto $(11,4 \mathrm{~kg})$, ocupó el cuarto lugar. Honduras, Nicaragua y El Salvador tuvieron indicadores generales inferiores a los del resto de los países de la región (tabla 4).

Tabla 4

Cantidad de plaguicidas importada en América Central por habitante, habitante rural, trabajador agrícola, superficie agrícola y pecuaria entre 2005 y 2009

Cantidad importada (kg ia/año)

\begin{tabular}{lcccccc}
\hline \multicolumn{5}{c}{ País } & Cantidad importada (kg ia/año) & \\
\cline { 2 - 7 } & Promedio & $\begin{array}{c}\text { Por } \\
\text { habitante }\end{array}$ & $\begin{array}{c}\text { Por } \\
\text { habitante } \\
\text { rural }\end{array}$ & $\begin{array}{c}\text { *Por } \\
\text { trabajador } \\
\text { agrícola }\end{array}$ & $\begin{array}{c}\text { Por } \\
\text { hectárea } \\
\text { agrícola }\end{array}$ & $\begin{array}{c}\text { Por } \\
\text { hectárea } \\
\text { pecuaria }\end{array}$ \\
\hline Costa Rica & 12293432 & 2,8 & 8,1 & 32,0 & 24,8 & 9,4 \\
Belice & 457443 & 1,6 & 2,8 & 19,4 & 4,5 & 9,1 \\
Guatemala & 13763412 & 1,0 & 2,4 & 5,0 & 5,8 & 6,8 \\
Panamá & 2510816 & 0,8 & 2,4 & 11,4 & 3,6 & 1,6 \\
Honduras & 5300968 & 0,7 & 1,5 & 4,7 & 3,7 & 3,1 \\
Nicaragua & 3131390 & 0,6 & 1,3 & 4,4 & 1,4 & 1,0 \\
El Salvador & 1814242 & 0,3 & 0,7 & 3,1 & 2,0 & 2,8 \\
América & $\mathbf{3 6 6 0 9 3 1 0}$ & $\mathbf{0 , 9}$ & $\mathbf{2 , 2}$ & $\mathbf{7 , 6}$ & $\mathbf{4 , 5}$ & $\mathbf{3 , 6}$ \\
Central & & & & & & \\
\hline
\end{tabular}

Fuente: Datos propios de la investigación.

*Se reduce a la cantidad de plaguicidas importada por Costa Rica y Guatemala el equivalente a la cantidad exportada de estas sustancias, que corresponde a $25 \%$ y $35 \%$ respectivamente.

Virya Bravo-Durán y otros.

Artículo protegido por licencia Creative Commons: BY-NC-ND / Protected by Creative Commons: BY-NC-ND

Revista de acceso y publicación gratuita/ Access and publication in Uniciencia is totally no fee. 
Uniciencia. Vol. 29, No. 2, pp. 84-106. Julio-Diciembre, 2015. URL: www.revistas.una.ac.cr/uniciencia

Email: revistauniciencia@una.cr
ISSN Electrónico: 2215-3470

DOI: http://dx.doi.org/10.15359/ru.29-2.6

Durante el quinquenio 2005-2009 se importaron en la región 91 ingredientes activos pertenecientes a las clases de toxicidad con mayor peligrosidad para la salud humana (tabla 5). Estos correspondieron a 124609 ton ia y representaron el 68\% de la cantidad total importada. Un $27 \%$ de la cantidad total importada correspondió a 48 ingredientes activos con toxicidad aguda de alta a extrema. Entre estos, paraquat, bromuro de metilo y clorotalonil representaron el 16\% de la importación de esta clase de peligrosidad (29 856 ton ia) (tabla 5). Un 35\% equivalió a 40 ingredientes activos que pueden presentar dos o más efectos tópicos en humanos, como alergénico o irritante de piel y ojos en grado de moderado a severo. El 2,4-D, paraquat y bromuro de metilo fueron el $27 \%$ de la importación de esta clase de peligrosidad (49 208 ton ia) (tabla 5). Un 47\% correspondiente a 21 ingredientes activos presentaron cuatro o más efectos crónicos como genotoxicidad, teratogenicidad, mutagenicidad, carcinogenicidad, neurotoxicidad o alteraciones endocrinas (tabla 5). El mancozeb, 2,4-D y paraquat constituyeron el $43 \%$ de la importación de esta clase de peligrosidad (79 495 ton ia).

De forma específica, se importaron plaguicidas con efectos genotóxicos en una proporción del total importado igual al 75\% (136 628 ton ia), neurotóxicos en una proporción del 74\% (136 288 ton ia), disruptores endocrinos en una proporción del 72\% (131 420 ton ia), cancerígenos en una proporción del 50\% (91 537 ton ia), teratogénicos en una proporción del 29\% (53 376 ton ia) y mutagénicos en una proporción del 16\% (29 967 ton ia).

\section{Tabla 5}

Cantidad de plaguicidas importada en América Central por clases de toxicidad peligrosa, entre 2005 y 2009

\begin{tabular}{|c|c|c|c|c|c|c|c|c|c|}
\hline \multirow{2}{*}{$\begin{array}{l}\text { Clases de } \\
\text { toxicidad } \\
\text { peligrosa }\end{array}$} & \multicolumn{6}{|c|}{ Cantidad importada (ton ia) } & \multirow{2}{*}{$\%$} & \multirow{2}{*}{ ia } & \multirow{2}{*}{$\begin{array}{l}\text { Plaguicidas más } \\
\text { importados }\end{array}$} \\
\hline & 2005 & 2006 & 2007 & 2008 & 2009 & Total & & & \\
\hline $\begin{array}{l}\text { Aguda, } \\
\text { alta a } \\
\text { extrema }\end{array}$ & 9629 & 9993 & 12692 & 10351 & 6674 & 49338 & 27 & 48 & $\begin{array}{l}\text { paraquat, bromuro de } \\
\text { metilo, clorotalonil, } \\
\text { metam sodio, terbufos, } \\
\text { etoprofos, metamidofos, } \\
\text { endosulfan, oxamil y } \\
\text { fenamifos }\end{array}$ \\
\hline $\begin{array}{l}\text { Tópica, } \\
\text { con } \geq 2 \\
\text { efectos } \\
\text { moderados } \\
\text { a severos }\end{array}$ & 13330 & 13628 & 16355 & 11910 & 9007 & 64231 & 35 & 40 & $\begin{array}{l}\text { 2,4-D, paraquat, bromuro } \\
\text { de metilo, clorotalonil, } \\
\text { tridemorf y } \\
\text { dicloropropeno }\end{array}$ \\
\hline $\begin{array}{l}\text { Crónica, } \\
\text { con } \geq 4 \\
\text { efectos }\end{array}$ & 16907 & 16984 & 21011 & 17327 & 14155 & 86384 & 47 & 21 & $\begin{array}{l}\text { mancozeb, } 2,4-\mathrm{D}, \\
\text { paraquat, diazinon y } \\
\text { carbendazim }\end{array}$ \\
\hline
\end{tabular}

Fuente: Datos propios de la investigación.

Virya Bravo-Durán y otros.

Artículo protegido por licencia Creative Commons: BY-NC-ND / Protected by Creative Commons: BY-NC-ND

Revista de acceso y publicación gratuita/ Access and publication in Uniciencia is totally no fee. 
Uniciencia. Vol. 29, No. 2, pp. 84-106. Julio-Diciembre, 2015. URL: www.revistas.una.ac.cr/uniciencia

En total se importaron del 2005 al 2009 en la región, 114141 ton ia de plaguicidas peligrosos, esta cantidad representó un 62\% del total importado y correspondió a 16 ingredientes activos (tabla 6). Entre los plaguicidas peligrosos, se identificaron 10 ingredientes activos con peligro agudo, 6 con peligro por efectos tópicos y 5 con peligro por efectos crónicos. Algunos de estos plaguicidas se seleccionaron por presentar varias clases de peligro, como por ejemplo el paraquat por peligro agudo, tópico y crónico, el 2,4D por peligro tópico y crónico, el bromuro de metilo y el clorotalonil por peligro agudo y tópico (tabla 6).

Los cinco plaguicidas peligrosos más importados fueron: mancozeb (36 779 ton ia), 2,4-D (24 917 ton ia), paraquat (17 800 ton ia), bromuro de metilo (6 492 ton ia) y clorotalonil (5 565 ton ia). Estos constituyeron el $50 \%$ del total importado por la región durante el quinquenio estudiado (tabla 6).

Tabla 6

Cantidad de plaguicidas importada en América Central por efectos tóxicos relevantes, entre 2005 y 2009

\begin{tabular}{|c|c|c|c|c|c|c|c|c|c|c|c|c|}
\hline \multirow{2}{*}{$\begin{array}{c}\text { Plaguicidas } \\
\text { peligrosos }\end{array}$} & \multicolumn{2}{|c|}{ Cantidad } & \multirow{2}{*}{$\frac{\text { T. aguda }}{\text { A - E }}$} & \multicolumn{3}{|c|}{ T. tópica } & \multicolumn{6}{|c|}{ T. crónica } \\
\hline & ton ia & $\%$ & & $\mathbf{O}$ & D & $\mathbf{A}$ & $\mathbf{N}$ & $\mathbf{T}$ & DE & $\mathbf{M}$ & $\mathrm{C}$ & G \\
\hline mancozeb & 36779 & 20,1 & & & & $\dagger$ & $\dagger$ & & $\dagger$ & & $\dagger$ & $\dagger$ \\
\hline $2,4-\mathrm{D}$ & 24917 & 13,6 & & $\dagger$ & $\dagger$ & & $\dagger$ & $\dagger$ & $\dagger$ & & $\dagger$ & $\dagger$ \\
\hline paraquat & 17800 & 9,7 & $\dagger$ & $\dagger$ & $\dagger$ & & $\dagger$ & $\dagger$ & $\dagger$ & $\dagger$ & & $\dagger$ \\
\hline $\begin{array}{l}\text { bromuro de } \\
\text { metilo }\end{array}$ & 6492 & 3,5 & $\dagger$ & $\dagger$ & $\dagger$ & & $\dagger$ & & & $\dagger$ & & \\
\hline clorotalonil & 5565 & 3,0 & $\dagger$ & $\dagger$ & $\dagger$ & & & & & & $\dagger$ & $\dagger$ \\
\hline metam sodio & 3947 & 2,2 & $\dagger$ & $\dagger$ & & & & & $\dagger$ & & $\dagger$ & $\dagger$ \\
\hline tridemorf & 3386 & 1,8 & & $\dagger$ & $\dagger$ & & & & & & & \\
\hline dicloropropeno & 2686 & 1,5 & & $\dagger$ & $\dagger$ & & & & & & $\dagger$ & $\dagger$ \\
\hline terbufos & 2540 & 1,4 & $\dagger$ & & & & $\dagger$ & & & & & $\dagger$ \\
\hline etoprofos & 1871 & 1,0 & $\dagger$ & & & & $\dagger$ & & & & & \\
\hline metamidofos & 1761 & 1,0 & $\dagger$ & & & & $\dagger$ & $\dagger$ & & & & $\dagger$ \\
\hline diazinon & 1640 & 0,9 & & & & $\dagger$ & $\dagger$ & $\dagger$ & $\dagger$ & $\dagger$ & & $\dagger$ \\
\hline endosulfan & 1384 & 0,8 & $\dagger$ & & & & $\dagger$ & & $\dagger$ & & & $\dagger$ \\
\hline oxamil & 1234 & 0,7 & $\dagger$ & $\dagger$ & & & $\dagger$ & & & & & $\dagger$ \\
\hline fenamifos & 1106 & 0,6 & $\dagger$ & & & & $\dagger$ & & & & & \\
\hline carbendazim & 1032 & 0,6 & & $\dagger$ & & & & $\dagger$ & $\dagger$ & & $\dagger$ & $\dagger$ \\
\hline Total & 114141 & 62,4 & & & & & & & & & & \\
\hline
\end{tabular}

Fuente: Datos propios de la investigación. Nota: Toxicidad aguda: alta a extrema (A-E) - Toxicidad tópica: moderada a severa como irritante ocular (O), dérmico (D) y alergéno (A) - Toxicidad crónica: neurotoxicidad $(\mathrm{N})$, teratogenicidad $(\mathrm{T})$, disrupción endocrina $(\mathrm{DE})$, mutagenicidad $(\mathrm{M})$, carcinogenicidad $(\mathrm{C})$ y genotoxicidad $(\mathrm{G})$.

Virya Bravo-Durán y otros.

Artículo protegido por licencia Creative Commons: BY-NC-ND / Protected by Creative Commons: BY-NC-ND

Revista de acceso y publicación gratuita/ Access and publication in Uniciencia is totally no fee. 
En América Central, entre 2005 y 2009, se importaron 15 ingredientes activos regulados en convenios internacionales. En orden de cantidad importada, estos fueron: paraquat, bromuro de metilo, terbufos, etoprofos, metamidofos, clorpirifos, endosulfan, carbofuran, metomil, metil paration, fosfuro de aluminio, paration, aldicarb, monocrotofos y lindano.

Los siete primeros ingredientes activos se importaron en cantidades $>1000$ ton ia en el periodo, mientras que del lindano solo existió una importación de 1,5 kg ia realizada por Belice en 2005 (tabla 7).

La tendencia en las cantidades importadas de estos siete plaguicidas decreció, en el caso del bromuro de metilo estas pasaron de 1745 ton ia en 2005 a 715 ton ia en 2009; en el de paraquat estas comenzaron a decrecer a partir del 2008; en el de terbufos, metamidofos y clorpirifos descendieron a partir del 2007 y para etoprofos y endosulfan bajaron solo en 2009. La cantidad total importada de los plaguicidas incluidos en convenios fue de 35012 ton ia, que representó el 19\% de las importaciones. Los ingredientes activos regulados por convenios internacionales y con mayor cantidad importada fueron los enmarcados en RESSCAD con $15 \%$ y PAN con $10 \%$, en ambos convenios el paraquat el plaguicida más importado. Del convenio de Estocolmo solo se importó el lindano en Belice.

Tabla 7

Número y cantidad de plaguicidas importada en América Central por su inclusión en convenios internacionales, entre 2005 y 2009

\begin{tabular}{|c|c|c|c|c|c|c|c|c|c|}
\hline \multirow{2}{*}{ Convenios } & \multicolumn{6}{|c|}{ Cantidades importadas (ton i.a) } & \multirow{2}{*}{ ia } & \multirow{2}{*}{$\%$} & \multirow{2}{*}{$\begin{array}{l}\text { Plaguicidas más } \\
\text { importados }\end{array}$} \\
\hline & 2005 & 2006 & 2007 & 2008 & 2009 & Total & & & \\
\hline PAN & 2900 & 3086 & 5737 & 3604 & 2905 & 18232 & 5 & 10,0 & paraquat \\
\hline RESSCAD & 5424 & 5232 & 8159 & 5573 & 4065 & 28453 & 12 & 15,5 & $\begin{array}{l}\text { paraquat, bromuro de } \\
\text { metilo, terbufos, } \\
\text { etoprofos, clorpirifos y } \\
\text { endosulfan }\end{array}$ \\
\hline Rotterdam & 765 & 351 & 570 & 422 & 65 & 2174 & 5 & 1,2 & metamidofos \\
\hline Estocolmo & 0 & 0 & 0 & 0 & 0 & 0 & 0 & 0,0 & \\
\hline Montreal & 1745 & 1556 & 1405 & 1071 & 715 & 6492 & 1 & 3,5 & bromuro de metilo \\
\hline Total & 7185 & 6801 & 9578 & 6654 & 4794 & 35012 & 15 & 19,1 & \\
\hline
\end{tabular}

Fuente: Datos propios de la investigación.

Virya Bravo-Durán y otros.

Artículo protegido por licencia Creative Commons: BY-NC-ND / Protected by Creative Commons: BY-NC-ND

Revista de acceso y publicación gratuita/ Access and publication in Uniciencia is totally no fee. 
Uniciencia. Vol. 29, No. 2, pp. 84-106. Julio-Diciembre, 2015. URL: www.revistas.una.ac.cr/uniciencia

Email: revistauniciencia@una.cr
ISSN Electrónico: 2215-3470

DOI: http://dx.doi.org/10.15359/ru.29-2.6

\section{Discusión}

Comparando la importación de plaguicidas en América Central durante los dos primeros quinquenios del presente siglo, se observó una tendencia a disminuir el número de ingredientes activos, que pasaron de 403 a 353 del primero al segundo quinquenio. Sin embargo, al comparar las cantidades importadas de plaguicidas la tendencia observada fue creciente, puesto que las cantidades aumentaron de 163918 ton ia en el primer quinquenio a 183047 ton ia en el segundo quinquenio. Esto significa que se están importando menos ingredientes activos, pero en mayor cantidad.

Igual que en el quinquenio 2000-2004, el más alto porcentaje de la importación (77\%) se concentró en pocos ingredientes activos (14 ia), entre los cuales el fungicida mancozeb fue también el plaguicida más importado con 37000 ton, lo que representó un $20 \%$ de la cantidad total importada durante ese período en la región. Costa Rica importa la mitad de esta cantidad para el control de la Sigatoka negra (Mycosphaerella fijiensis) en banano (Bravo et al., 2013; Ramírez et al., 2009); no obstante, su uso aquí y en otros países también es recomendado en muchos cultivos para el control de otras enfermedades como Phytophthora infestans, Botrytis cinerea, Alternaria spp., Septoria spp. (Gepp y Mondino, 2013). Entre periodos, no se observó una gran diferencia en la cantidad importada de mancozeb, el cual tan solo aumentó 6302 ton ia, lo que porcentualmente es poco (Bravo et al., 2011).

Al comparar la cantidad total importada de plaguicidas por año por cada uno de los países de la región, se observó que, en 2005-2009, Guatemala (13 763 ton ia) ocupó el primer lugar y Costa Rica el segundo (12 293 ton ia) (figura 1). Este comportamiento fue inverso al de 2000-2004, en el que Costa Rica ocupó el primer lugar (Bravo et al., 2011). Esto se explica porque Guatemala en 2007 importó una cantidad tres veces más alta que la de Costa Rica en el mismo periodo. Sin embargo, Ruano, citado por Larios (2011) menciona que la importación de plaguicidas en Guatemala bajó, en 2008, con la caída de los precios internacionales del petróleo, pero que volvió a estabilizarse en 2009.

En promedio, la cantidad de plaguicidas importada por los países de la región de 2005 a 2009 creció con respecto a la cantidad importada de 2000 a 2004 (figura 2). Los países con mayor crecimiento fueron Guatemala y Costa Rica, al igual que en el período anterior. Esto puede ser resultado de la formulación y envasado de plaguicidas para exportación que se da en sus territorios.

Honduras fue el único país que exhibió un descenso en la importación para el 2009, aunque mostró un aumento de 2005 a 2008. Recordemos que durante el quinquenio anterior para Honduras se trabajó con bases de datos provenientes de tres fuentes de información y se estimaron cantidades importadas por año muy fluctuantes, que hacían dudar de la consistencia de la información (Bravo et al., 2011). Este fenómeno podría estar influyendo nuevamente.

Virya Bravo-Durán y otros.

Artículo protegido por licencia Creative Commons: BY-NC-ND / Protected by Creative Commons: BY-NC-ND

Revista de acceso y publicación gratuita/ Access and publication in Uniciencia is totally no fee. 
Entre 2005 y 2009, se importó en América Central un promedio anual de plaguicidas correspondiente a 37000 ton ia, que equivalieron aproximadamente al 1.5\% de la producción mundial de plaguicidas (García, 1998; Grube et al., 2011; Chapagain-K, 2011). De esta cantidad, 38\% correspondieron a Guatemala, 34\% a Costa Rica, $14 \%$ a Honduras y el restante 14\% a importaciones de Nicaragua, Panamá, El Salvador y Belice, en orden decreciente. Esta distribución porcentual no fue muy diferente a la observada de 2000 a 2004, en la cual un tercio de la importación correspondía a Costa Rica, el otro a Guatemala y el último a los cinco países restantes (Bravo et al., 2011). Se enfatiza que el promedio de importación de plaguicidas para América Central fue subestimado aproximadamente en un $6 \%$ por la no inclusión de datos; en el caso de Nicaragua para dos años y en el de Guatemala para seis meses, que no fueron enviados por los Ministerios de Agricultura de estos países.

Sin embargo, con base en la información obtenida de años anteriores, se realizaron aproximaciones de 3000 ton ia/año para el 2008 y el 2009 en Nicaragua y de 6000 ton ia para el II semestre del 2009 en Guatemala y se calculó en 39000 ton ia/año el promedio ajustado para América Central, de 2005 a 2009. Con el fin de comparar este valor, se utilizaron las estadísticas de la CEPAL (ECLA, 2012) que incluyen la cantidad de herbicidas, fungicidas, bactericidas e insecticidas importados en América Central, durante el mismo período y se estimó con estas un promedio de importación equivalente a 35813 ton ia/año.

Un valor bastante similar al aquí reportado, si se toma en cuenta que las estadísticas de la CEPAL corresponden únicamente a cuatro acciones biocidas y que, además, cuando los países no reportan datos, la CEPAL omite cantidades importantes de plaguicidas importados, como son, en este caso, las correspondientes a Costa Rica (2005 a 2009), Panamá (2008 y 2009), Belice y Honduras (2005). De cualquier forma en que se estimara el promedio anual de importación de plaguicidas en la región para el quinquenio 2005-2009, el valor fue mayor que el del quinquenio 2000-2004, el cual se había calculado en 33000 ton ia/año (Bravo et al., 2011).

Los ingredientes activos más importados entre 2005 y 2009 por acción biocida (herbicidas: 2,4-D; fungicidas: mancozeb; fumigantes: bromuro de metilo; insecticidas: metamidofos y nematicidas: terbufos) fueron los mismos reportados para el periodo 20002004. La distribución porcentual de la cantidad de plaguicidas importada por acción biocida en este quinquenio tampoco difiere mucho del anterior, los herbicidas y los fungicidas continuaron liderando. Las cantidades importadas en total aumentaron de 2005 a 2009 en casi todas las acciones biocidas y estos aumentos fueron mayores en los herbicidas y los fungicidas (Bravo et al., 2011). Los fumigantes fueron la única acción biocida que decreció en este segundo quinquenio, debido a que los países de la región han venido realizando acciones de reducción gradual del bromuro de metilo, para cumplir con lo establecido en el Protocolo de Montreal. Tal es el caso de Costa Rica, que proyecta eliminar el uso del fumigante al concluir el 2013 (MINAE, 2013). 
Entre 2005 y 2009, los grupos químicos (tabla 2) y sus ingredientes activos principales (ditiocarbamatos: mancozeb, fenoxiacéticos: 2,4-D, fosfonoglicinas: glifosato, bipiridilos: paraquat, organofosforados: terbufos, triazinas: atrazina, alifáticos bromados: bromuro de metilo y benzonitrilos: clorotalonil) no fueron diferentes de los dominantes durante el periodo 2000-2004 (Bravo et al., 2011). Pero la cantidad importada mostró una tendencia creciente en casi todos los grupos, con excepción de los organofosforados, los alifáticos bromados y los benzonitrilos que disminuyeron su importación.

En el primer grupo el metamidofos, el metil paration y el terbufos bajaron sus importaciones de un periodo a otro en 1000 ton ia cada uno. En el caso del metamidofos, que en el primer quinquenio ocupa el cuarto lugar entre los más importados en Nicaragua, debe considerarse un ajuste de aproximadamente 300 ton ia por los datos faltantes de 2008 y 2009, o sea, que su merma real pudo ser de 700 ton ia en el segundo quinquenio. En el segundo grupo bromuro de metilo bajó en casi 5000 ton ia su importación y en el tercer grupo clorotalonil importó 2000 ton ia menos que en 2000-2004.

La tendencia mostrada de 2005 a 2009 por los indicadores generales de uso $(\mathrm{kg}$ ia/habitante/año; $\mathrm{kg}$ ia/habitante rural/año; $\mathrm{kg}$ ia/trabajador agrícola/año; $\mathrm{kg}$ ia/ha agrícola/año) en todos los países de la región no fue muy diferente de la encontrada entre 2000 y 2004. Costa Rica fue el país con los indicadores más altos de la región. Esto pudo ser el resultado del alto ingreso de plaguicidas a este país para uso agrícola, formulación, envasado y exportación; así como de la menor densidad de población total y rural, de trabajadores agrícolas y superficie agrícola y pecuaria con relación con otros países de la región.

En el primer quinquenio, se calculó solamente un indicador por superficie agrícola, que consideró únicamente las tierras con cultivos temporales (arables) y las dedicadas a cultivos permanentes y no se calculó ningún indicador para superficies pecuarias. Estas áreas, aunque usan plaguicidas en dosis bajas, cuentan con extensos territorios y el producto de ambos factores es el uso de cantidades altas de plaguicidas. Por ejemplo, en Costa Rica los pastos son equivalentes a 1300000 ha anuales (ECLA, 2012; FGG y MAG, 2007) y consumen en promedio $1 \mathrm{~kg}$ ia/ha/año, que en total representan 1300 ton ia/año, o sea, aproximadamente un $11 \%$ de la importación de plaguicidas del país.

Por tanto, para el quinquenio 2005-2009 se calculó un nuevo indicador para superficies pecuarias, utilizando datos de las áreas de pastos y praderas procedentes de las estadísticas de CEPAL (ECLA, 2012). La tendencia de este fue: Costa Rica a la cabeza, seguida por Belice con valores muy similares y Guatemala en tercera posición. Este indicador, en un próximo análisis de datos, podría afinarse descontando el área de praderas, para agrupar la restante área de pastos con el área agrícola y utilizar el resultado como denominador en el cálculo de un solo indicador de importación de plaguicidas por superficie agropecuaria.

Otro indicador que se ajustó para el segundo quinquenio analizado fue el correspondiente al de uso de plaguicidas por trabajador agrícola para Guatemala y Costa Rica. En estos dos países, la importación de plaguicidas no se hace exclusivamente con 
fines agrícolas sino también con fines industriales (química), los que consumen una buena proporción de la cantidad importada. El ajuste se realizó restándole a la cantidad de plaguicidas importada, la proporción exportada por las formuladoras y envasadoras, la que se estima en un 35\% para Guatemala (Larios, 2011) y hasta en un 25\% para Costa Rica (Ramírez et al., 2009).

Con los datos corregidos se calcularon los indicadores para estos dos países y se obtuvo una disminución en el indicador de 7,9 a $5 \mathrm{~kg}$ ia/año/trabajador agrícola en Guatemala y de 43,3 a $32 \mathrm{~kg}$ ia/año/trabajador agrícola en Costa Rica, para el periodo 2005-2009. A pesar de que el valor del indicador bajó, Costa Rica mantuvo la posición más alta de la región y Guatemala escaló una posición, pasando de quinto a cuarto lugar. Se espera, en un futuro, contar con mejores datos de exportación y de número de trabajadores agrícolas en la región, para poder, así, afinar este indicador. Otra alternativa sería calcular indicadores para trabajadores expuestos por sector, agrícola o industrial, pero se requieren, por país, datos más precisos de destino de las importaciones.

El número de ingredientes activos clasificados en las clases de toxicidad con mayor peligrosidad disminuyó a 91 para el quinquenio 2005-2009, con respecto a los 142 ia de plaguicidas importados para el quinquenio 2000-2004. La cantidad importada por estas clases de peligro siguió la tendencia general de menor número de ia y mayor cantidad importada. Esta pasó de 103295 ton ia (2000-2004) a 124609 ton ia (2005-2009), es decir, aumentó en 21314 ton ia (3\%) de un quinquenio a otro (Bravo et al., 2011).

Comparando ambos quinquenios por clases específicas de peligro, observamos que las cantidades de plaguicidas importadas aumentaron para la toxicidad aguda de alta a extrema en un $5 \%$ y para la crónica con cuatro o más efectos en un $17 \%$.

Por el contrario, la clase de peligro con dos o más efectos tópicos en grado de moderado a severo disminuyó en un $1 \%$. Es preocupante constatar que más del $70 \%$ de la cantidad importada correspondió a plaguicidas con efectos crónicos como genotóxicos, neurotóxicos y disruptores endocrinos y que un $50 \%$ tienen efectos cancerígenos. Además, la proporción de los disruptores endocrinos subió en un 3\% y la de los teratogénicos y cancerígenos aumentó en un 2\%, con respecto al periodo 2000-2004 (Bravo et al., 2011). Sería importante vincular estos datos con los reportes de vigilancia epidemiológica de los países, para tratar de encontrar las posibles relaciones y tomar las decisiones que sean oportunas en beneficio de la salud de los seres humanos.

En la definición de las clases de peligro se estableció, esta vez, un límite arbitrario relacionado con la cantidad de ia importada (> 1000 ton ia/periodo). Así se identificó un grupo de 16 ingredientes activos (tabla 6) como relevantes para la vigilancia epidemiológica en la región, pues tienen características que los hacen peligrosos para la salud humana. Tres de estos plaguicidas peligrosos (mancozeb, 2,4-D y paraquat) fueron importados de 2005 a 2009 en cantidades superiores a las 17000 ton ia y su aumento respectivo fue de 6302 ton, 2763 ton y 5988 ton en relación con lo importado en el periodo 2000-2004. Mancozeb, aunque sin una toxicidad aguda alta según la OMS, sí posee efectos tópicos oculares (leves), capacidad como alergeno y efectos crónicos de 
neurotoxicidad (incluyendo Parkinson), disrupción endocrina, genotoxicidad y es posiblemente cancerígeno de acuerdo con su clasificación en EPA (de la Cruz et al., 2013). En las investigaciones realizadas por el IRET en Costa Rica, se ha determinado la existencia de: 1) riesgos de cáncer y efectos neurotóxicos en trabajadores expuestos a plaguicidas (Wesseling, 1997), y 2) relación con leucemia en niños con padres expuestos a plaguicidas (Monge, 2006).

La cantidad importada de plaguicidas incluidos en convenios internacionales para su regulación aumentó de 28 millones de $\mathrm{kg}$ ia (2000-2004) a 35 millones de kg ia (20052009). En términos de ingredientes activos y porcentajes del total importado, los datos obtenidos mostraron igual comportamiento que la importación general, menos ingredientes activos (16 a 15), pero en más cantidad importada (17\% a 19\%). La proporción de los plaguicidas incluidos en RESSCAD fue muy similar a la del primer quinquenio (15\% a 15.5\%) (Bravo et al., 2011).

Las importaciones de plaguicidas incluidos en PAN, RESSCAD y Rotterdam decrecieron después del 2007, posiblemente debido a la puesta en práctica de decretos regulatorios en los países, aunque también podría ser un efecto de las importaciones faltantes de Nicaragua (2008 y 2009) y Guatemala (julio-diciembre 2009).

Las importaciones de bromuro de metilo, que mermaron en 2004 por la sobreproducción de melón y la caída de los precios internacionales, continuaron bajando de 2005 a 2009, debido a las acciones de reducción de este fumigante establecidas por los países de la región para el cumplimiento del Protocolo de Montreal. La región continuó con el cumplimiento del Convenio de Estocolmo y no importó ningún plaguicida COP.

Son muchos y sólidos los datos que en diez años se han generado en relación con la importación de plaguicidas en la región centroamericana y los peligros asociados con la salud. Presentar esta información a la comunidad de forma resumida en una revista científica resulta difícil.

Se propone constituir en la región una red y un foro de personas expertas, con comunicación vía internet y acceso en línea a una base de datos de importación de plaguicidas y toxicidad, en la que puedan aportar a la construcción de conocimientos desde sus respectivas experticias. Esta base podría articularse con un módulo de consultas que pueda ser empleado por quienes deben tomar las decisiones y el público en general, para asumir la vigilancia de los plaguicidas como una responsabilidad compartida.

En Costa Rica, luego de la fase de transición de SALTRA, estando aún sin aprobar la fase II, el IRET continuó con el desarrollo de indicadores y su divulgación. Entre estos se encuentran: 1) indicadores de ambiente con datos de importaciones para América Central (2000-2004), 2) indicadores de salud y ambiente con datos de importaciones para Costa Rica (1980-2009), 3) indicadores de salud con datos de uso de plaguicidas para 10 cultivos en Costa Rica y 4) indicadores de salud para América Central (2005-2009).

Los dos primeros grupos de indicadores fueron presentados en un congreso científico internacional y hay tres publicaciones en proceso. El tercer grupo de indicadores 
ya fue publicado y en el cuarto grupo se basa la presente publicación, incluida posteriormente en SALTRA fase II. Además, el IRET ha establecido una colaboración con el Ministerio de Agricultura y Ganadería de Costa Rica para introducir mejoras en las bases de importaciones y desarrollar proyectos con buenas prácticas agrícolas. En el 2014 el programa SALTRA, reactivado con recursos de la Unión Europea, incluyó los indicadores en una nueva propuesta regional, en la cual se busca que cada país se apropie de la metodología y desarrolle sus indicadores.

En concordancia con los datos presentados, se concluye que las poblaciones humanas expuestas a plaguicidas en América Central continúan en peligro. En virtud de lo anterior, se insta a los países de la región a emprender pasos en la reducción de la importación y uso de plaguicidas peligrosos. En este sentido, la Asamblea Legislativa de El Salvador dio, en 2013, un importante avance para proteger la salud de la población, al considerar la reforma de las leyes sobre agroquímicos y contemplar la prohibición de 53 plaguicidas y el fomento de buenas prácticas agrícolas (Chavarría, 2013). Aunque esta iniciativa aún no prosperó, queda la esperanza de que, al menos, anuncie un cambio.

\section{Agradecimientos}

Los autores agradecemos a la Universidad Nacional los recursos dados para la investigación y al Programa Salud y Trabajo en América Central el apoyo para su regionalización, mediante el enlace con la Universidad de San Carlos (Guatemala), Universidad de El Salvador, Universidad Nacional de Honduras, Universidad Nacional Autónoma de Nicaragua y Universidad de Panamá.

Reconocemos y agradecemos la colaboración brindada por los funcionarios del Pesticides Control Board en Belice, del Ministerio de Agricultura y Ganadería en Guatemala, de la Secretaria de Agricultura y Ganadería en Honduras, del Ministerio de Agricultura y Ganadería en El Salvador, del Ministerio de Agricultura, Ganadería y Forestales en Nicaragua, del Ministerio de Agricultura y Ganadería en Costa Rica y del Ministerio de Desarrollo Agropecuario en Panamá.

\section{Referencias}

Banco Mundial (BM). (2013). Indicadores de trabajo y protección social. Banco de datos. Recuperado de http://datos.bancomundial.org/indicador/SL.TLF.TOTL.IN

Bravo, V., de la Cruz, E., Herrera, G. y Ramírez, F. (2013). Uso de plaguicidas en cultivos agrícolas como herramienta para el monitoreo de peligros en salud. Revista Uniciencia, 27(1), 351-376. Recuperado de http://www.revistas.una.ac.cr/index.php/uniciencia/issue/view/445

Bravo, V., Rodríguez, T., van Wendel de Joode, B., Canto, N., Calderón, G. R., Turcios, M., Menéndez, L. A., Mejía, W., Tatis, A., Abrego, F., de la Cruz, E. y Wesseling, C. (2011). Monitoring pesticide use and associated health hazards in Central

Virya Bravo-Durán y otros.

Artículo protegido por licencia Creative Commons: BY-NC-ND / Protected by Creative Commons: BY-NC-ND

Revista de acceso y publicación gratuita/ Access and publication in Uniciencia is totally no fee. 
Uniciencia. Vol. 29, No. 2, pp. 84-106. Julio-Diciembre, 2015.

America. International Journal of Occupational and Environmental Health, 17(3), 258-269. http://dx.doi.org/10.1179/oeh.2011.17.3.258

Chapagain-K, R. (2011). Regulación internacional del uso de pesticidas: La experiencia de Costa Rica. Revista Costarricense Salud Pública, 20(2), 124-129.

Chavarría, R. (5 de septiembre, 2013). Reportaje: Diputados prohíben uso de 53 agroquímicos en el país. La Prensa Gráfica. El Salvador. Recuperado de http://www.laprensagrafica.com/2013/09/06/diputados-prohiben-uso-de-53agroquimicos-en-el-pais

Comisión Económica para América Latina y el Caribe (ECLA). (2012). Anuario Estadístico de América Latina y el Caribe. División de Estadísticas. Recuperado de http://www.cepal.org/cgibin/getprod.asp?xml=/deype/noticias/paginas/9/39579/P39579.xml\&xsl=/deype/tpl/ p18f.xsl\&base=/deype/tpl/top-bottom.xsl

de la Cruz, E., Bravo, V. y Ramírez, F. (2013). Plaguicidas de Centroamérica. Instituto Regional de Estudios en Sustancias Tóxicas, Universidad Nacional. Costa Rica. Recuperado de http://www.plaguicidasdecentroamerica.una.ac.cr/

Federación de Cámaras de Ganaderos de Guanacaste (FGG) y Ministerio de Agricultura y Ganadería (MAG). (2007). Plan estratégico para el desarrollo de la agrocadena de la ganadería bovina de carne en la Región Chorotega. Guanacaste, Costa Rica: Informe técnico.

García, J. E. (1998). Intoxicaciones agudas con plaguicidas: Costos humanos y económicos. Revista Panamericana de Salud Pública, 4(6), 383-387. http://dx.doi.org/10.1590/S1020-49891998001200003

Gepp, V. y Mondino, P. (2013). Apuntes sobre fungicidas. Unidad de Fitopatología, Departamento de Protección Vegetal, Facultad de Agronomía, Universidad de la República. Uruguay. Recuperado de http://www.pv.fagro.edu.uy/cursos/pvh/DocsPVH/Apuntes_Fungicidas.pdf

Grube, A., Donaldson, D., Kiely, T. y Wu, L. (2011). Pesticides industry sales and usage, 2006 and 2007 market estimates. United States Environmental Protection Agency. Recuperado de http://www.epa.gov/opp00001/pestsales/07pestsales/market_estimates2007.pdf

Larios, R. (24 de enero, 2011). Reportaje: La importación de los plaguicidas sube un 11.1\%. SIGLO21.com.gt, Suplemento Pulso Económico. Recuperado de http://www.s21.com.gt/node/28335

Ministerio de Ambiente y Energía de Costa Rica (MINAE). (24 de septiembre, 2013). Reportaje: Reconocen al país por sus logros en la proyección de la capa de ozono. Departamento de Prensa. Anuncios MINAE. Recuperado de http://www.minae.go.cr/index.php/actualidad/anuncios/60-reconocen-al-pais-porsus-logro-en-la-proteccion-de-la-capa-de-ozono

Monge, P. (2006). Occupational exposure to pesticides and risk of leucemia among offspring in Costa Rica (Tesis doctoral). Karolinska University, Sweden.

Nieto, O. (2001). Fichas técnicas de plaguicidas a prohibir o restringir incluidos en el Acuerdo No 9 de la XVI Reunión del Sector Salud de Centroamérica y República 
Uniciencia. Vol. 29, No. 2, pp. 84-106. Julio-Diciembre, 2015.

Dominicana (RESSCAD). Organización Panamericana de la Salud. Recuperado de http://www.rapal.org/db_files/PlaguiAL_InfoPa_RepDominicana_FichasTecnicasRESSCAD_Jul0 $\underline{1 . p d f}$

Olivera, S. y Rodríguez, D. (1999). Pesticidas, salud y ambiente. Revista Posdata del Instituto Clemente Estable, 259, 80-82.

Partanen, T. y Aragón, A. (2009). Informe regional: Perfiles de salud ocupacional en América Central. Serie Salud y Trabajo $N^{\circ}$. Heredia, Costa Rica: Programa Salud y Trabajo, Instituto Regional de Estudios en Sustancias Tóxicas, Universidad Nacional.

Pesticide Action Network International (PAN). (2009). The list of lists. A catalogue of lists of pesticides identifying those associated with particularly harmful health or environmental impacts. Recuperado de http://www.pan-uk.org/publications/list-of$\underline{\text { lists-2009 }}$

Proyecto Aspectos Ocupacionales y Ambientales de la Exposición a Plaguicidas en el Istmo Centroamericano (PLAGSALUD). (2002). Situación epidemiológica de las intoxicaciones agudas por plaguicidas en el istmo centroamericano, 1992-2000. Boletín Epidemiológico de la Organización Panamericana de la Salud, 23(3), 5-9.

Ramírez, F., Chaverri, F., de la Cruz, E., Wesseling, C., Castillo, L. y Bravo, V. (2009). Importación de plaguicidas en Costa Rica. Periodo 1977-2006. Informes Técnicos IRET $N^{\circ}$ 6. Heredia, Costa Rica: Instituto Regional de Estudios en Sustancias Tóxicas, Universidad Nacional.

Secretaría del Convenio de Estocolmo. (2009). Convenio de Estocolmo sobre contaminantes orgánicos persistentes. Texto y anexos. Programa de las Naciones Unidas para el Medio Ambiente. Recuperado de http://www.wipo.int/edocs/trtdocs/es/unep-pop/trt_unep_pop_2.pdf

Secretaría del Convenio de Rotterdam. (2004). Convenio de Rotterdam sobre el procedimiento de consentimiento fundamentado previo aplicable a ciertos plaguicidas y productos químicos peligrosos objeto de comercio internacional. Texto y anexos. Organización de las Naciones Unidas para la Agricultura y la Alimentación. Recuperado de http://www.pic.int

Secretaría del Ozono. (1997). Protocolo de Montreal relativo a las sustancias que agotan la capa de ozono. Programa de las Naciones Unidas para el Medio Ambiente. Recuperado de http://ozone.unep.org/spanish/Treaties_and_Ratification/2B_montreal_protocol.sht $\underline{\mathrm{ml}}$

University of Hertfordshire. (2012). Footprint pesticide properties database. Unidad de Investigación en Medio Ambiente y Agricultura. Recuperado de http://www.eufootprint.org/ppdb.html

Weinberg, J. (2009). Guía para las ONG sobre los plaguicidas peligrosos y el SAICM. Marco de acción para proteger la salud humana y el medio ambiente de los plaguicidas peligrosos. International Pops Elimination Network. Recuperado de http://ipen.org/sites/default/files/documents/ngo_guide_hazpest_saicm-es.pdf 
Uniciencia. Vol. 29, No. 2, pp. 84-106. Julio-Diciembre, 2015.

Wesseling, C. (1997). Health effects from pesticide use in Costa Rica - an epidemiologic approach (Tesis doctoral). Karolinska University, Sweden.

Wesseling, C., Aragón, A., Castillo, L., Corriols, M., Chaverri, F., de la Cruz, E., Keifer, M., Monge, P., Ruepert, C. y van Wendell, B. (2001). Plaguicidas peligrosos en América Central. International Journal of Occupational and Environmental Health, 7(4), 287-294. http://dx.doi.org/10.1179/oeh.2001.7.4.287

World Bank (WB). (2008). Agriculture for Development, world development report 2008. Recuperado de http://siteresources.worldbank.org/INTWDR2008/Resources/WDR_00_book.pdf

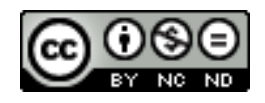

Evaluación del Importación de plaguicidas y peligros en salud en América Central durante el periodo 2005 - 2009. (Virya Bravo-Durán y otros) por Revista Uniciencia se encuentra bajo una Licencia CreativeCommons AtribuciónNoComercial-SinDerivadas 3.0 Unported. 